\title{
Make or take scenario
}

\author{
An assessment of future ecosystem services and human well-being in the Great Barrier Reef region, led \\ by social-ecological system scientist Erin Bohensky, draws on expertise in ecology, economics, sociology, \\ geography, hydrology and oceanography.
}

\begin{abstract}
What was the impetus for this project? What was the main objective of the work at the beginning of the project?

The objective for this project was to develop scenarios, or narratives of possible futures, for the Great Barrier Reef region. The impetus for the project came from an international workshop held in Townsville, Australia, which aimed to raise awareness among the attendees - and among government agencies in particular - about the future outlook for the Great Barrier Reef. We undertook a scenario analysis to explore whether global and regional development is currently defined purely in terms of economic growth or more broadly in terms of human well-being and environmental sustainability, and hence in terms of how climate change is addressed. The scenarios suggest that if climate change is not mitigated, the Great Barrier Reef may become a fundamentally different system by 2100 , and that management of global and regional pressures will be needed to maintain its full range of ecosystem services. The future of the region will depend on whether national and regional authorities become active future makers or passive future takers in response to global drivers of change.
\end{abstract}

How did you find suitable collaborators? It was very much a self-selection process. Invitations to attend the workshop were sent widely to people involved with research on the Great Barrier Reef. There were quite a few people initially involved, but it was a two-week workshop and some could only attend for a day, so those who were interested in staying longer and contributing became part of the team.

Did any difficulties arise in working with a team of experts with different research backgrounds and perspectives?

There weren't major difficulties, but there were different opinions and disagreements, which we had to work through by communicating. I also think that respect for each other's work helped the team work through those differences in opinion. We also had some social events during the two weeks of the workshop that were important for trust building. And making time for communication was really important after the workshop.

What was the highlight of working with an interdisciplinary team?

We had a really great group of people who worked well together, respecting each other's expertise even though everyone was working on a different piece of the puzzle. It was also a very diverse team in terms of gender, age and country of origin, and I think this diversity added to the perspective.

\section{Any surprises?}

It was surprising how everyone was receptive to this idea of scenario analysis, which sometimes is more an art than a science. Many scientists are accustomed to more

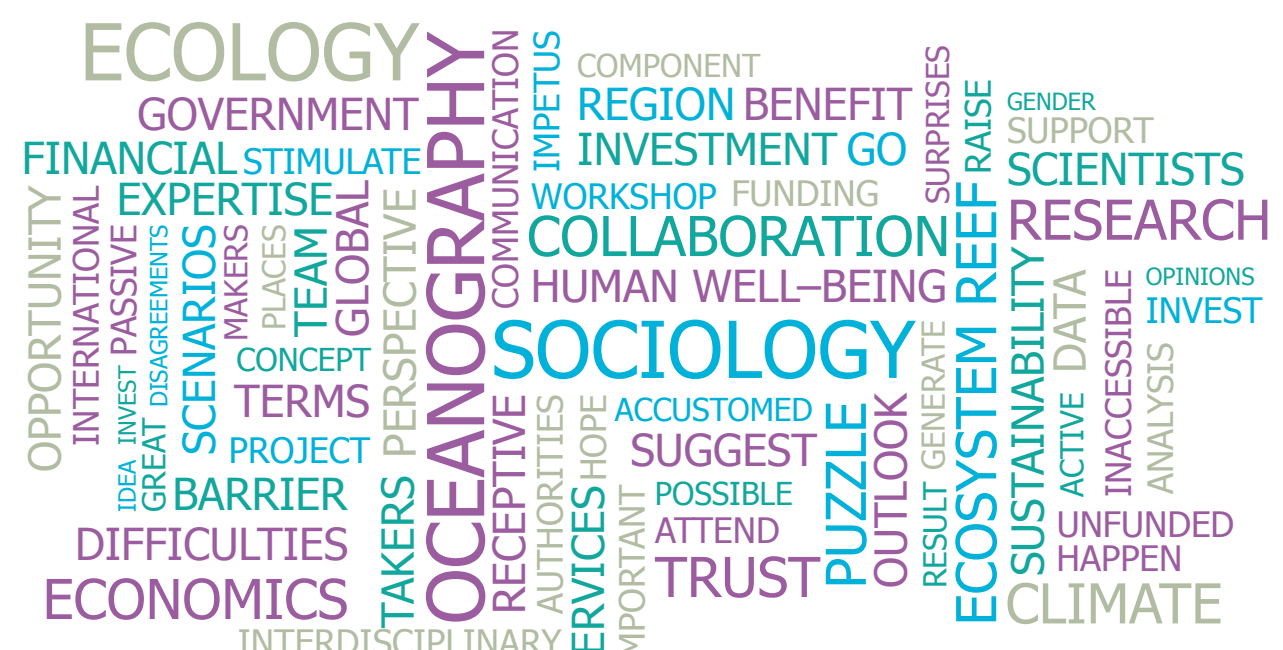

conventional approaches, whereas scenarios push the boundaries. The other surprise was that there isn't as much available data for the Great Barrier Reef as one might think.

Did you learn any lessons about interdisciplinary collaboration from this project that would benefit others trying to do similar work?

The most important thing is that an interdisciplinary collaboration is a kind of social process where you need to invest that extra time to get to know each other personally, as communication is really critical.

Was it difficult to get financial support and what would you suggest to researchers looking for funding to carry out interdisciplinary work?

We didn't really get financial support for the research. The workshop was supported by different institutions, but we didn't receive any direct support to carry out the work. It is difficult to get funding for research on scenarios as the concept is often inaccessible to funders. Sometimes the best thing that can happen is that a window of opportunity opens, and the value of scenarios to respond to that opportunity suddenly becomes apparent. That said, as a result of our work, a scenario component is being included in several new projects. Sometimes you have to take that first step of doing unfunded work to produce something that can generate funding commitments.

\section{Any final thoughts?}

I hope that this collaboration may stimulate some thinking among people with decisionmaking power about what the Great Barrier Reef region may become in the future. But I also hope that it will stimulate thinking about the future more generally. The concept of future makers or future takers in our paper is certainly relevant in places other than just the Great Barrier Reef. And thinking about the future is inherently interdisciplinary!

\section{INTERVIEW BY MONICA CONTESTABILE}

This Beyond Boundaries is based on the work by Erin Bohensky and colleagues, published in Glob. Environ. Change doi: 10.1016/ j.gloenvcha.2011.03.009 (2011). 